\title{
Literary critic: Pandit Gopinatha Nandasharma
}

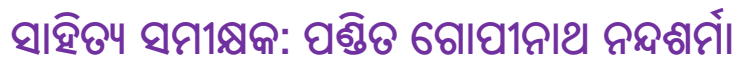

Bijayalaxmi Dash a, ${ }^{*}$

a Department of Odia, Ravenshaw University, Odisha 753003, India
*Corresponding author Email: Rudrabijayalaxmi@gmail.com
DOI: https://doi.org/10.34256/ijmrd2011
Received: $19-09-2020 ;$ Accepted: $24-10-2020 ;$ Published: $30-10-2020$

Abstract: Pandit Gopinath Nandasharma, is a well-known Odia linguist, lexicographer, translator, poet, writer and scholar. Pandit Nanda Sharma is the first Odia dictionary writer who had completed the work for this dictionary in 1903, which was published in 1916. He is known as the Panini of Odia Sahitya. In this paper I emphasized the critical outlook of Pandit Gopinath Nanda Sharma regarding "Sarala Mahabharata written by "sudra muni" Sarala Das, who belongs to the $15^{\text {th }}$ century, is known as the first major poet (the aadi kavi) of Odia literature.

Keywords: Pandit Gopinath Nandasharma, Panini of Odia Sahitya, Lexicographer, Linguist, Sarala Mahabharat.

Language: Odia

\section{About the Author}

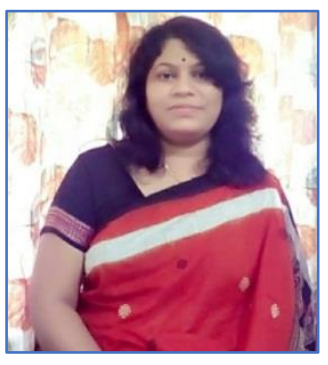

Dr. Bijayalaxmi Dash Ph.D currently working as a lecturer in the P.G Department of Odia, Ravenshaw University, Cuttack. Completed her B.A. and M.A (Oriya) with first-class from Ravenshaw College, Cuttack affiliated to Utkal University Odisha. Obtained her M.Phil with specialization in Modern Poetry from Ravenshaw College and was awarded a Ph.D. in 2011 by Utkal University, Vani Vihar, Bhubaneswar, Odisha. She is interested in the study of Language \& Modern Literature, and the Study of Folk Culture and Literature.

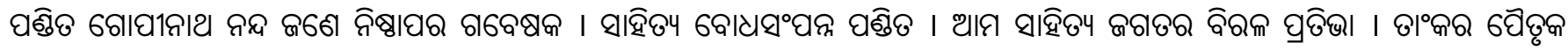

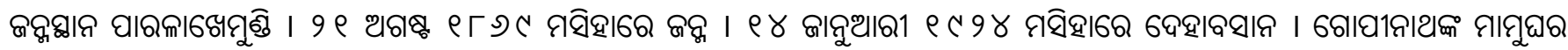

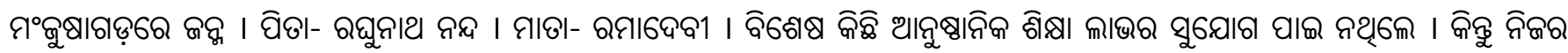

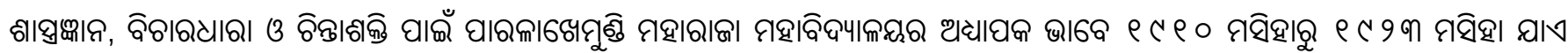

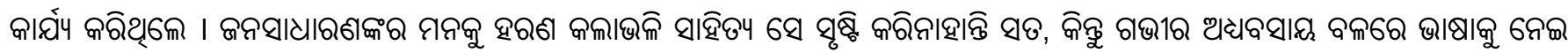

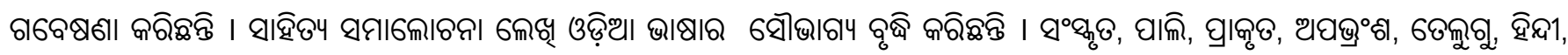

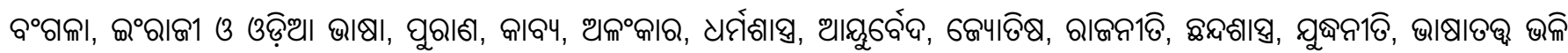

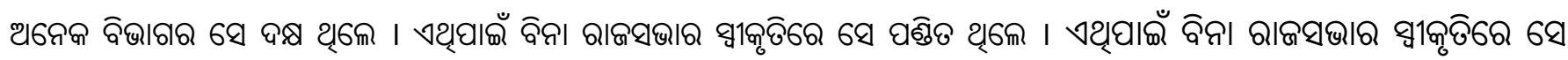

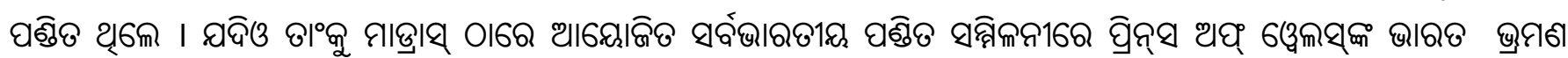

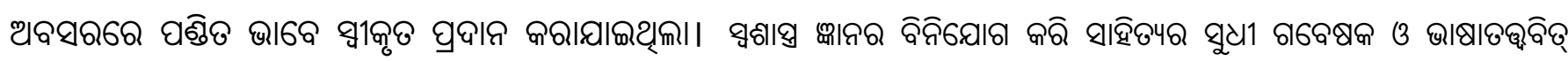

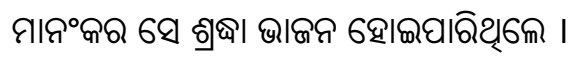


(9)

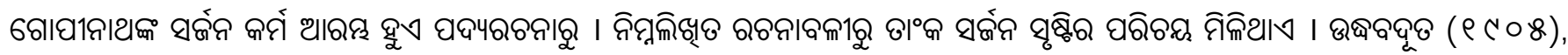

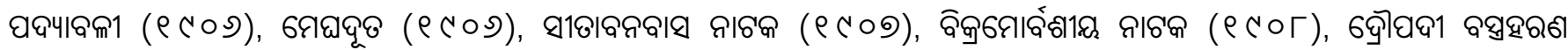

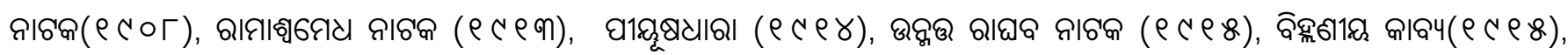
ต।

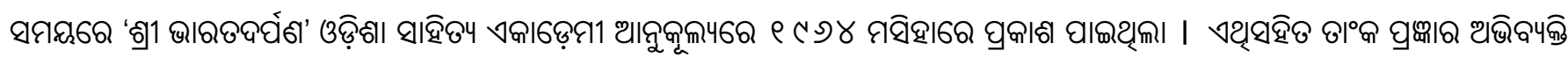

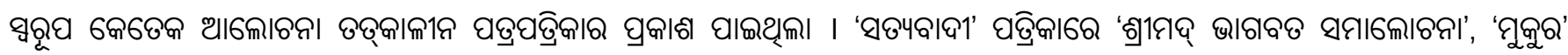

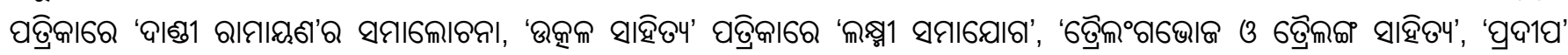

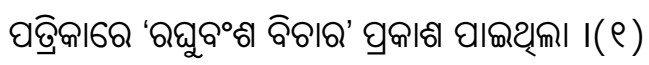

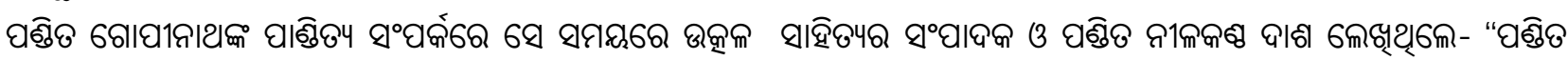

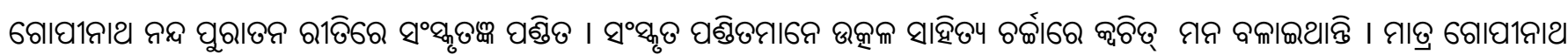

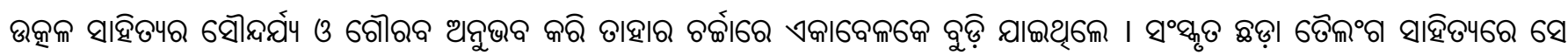

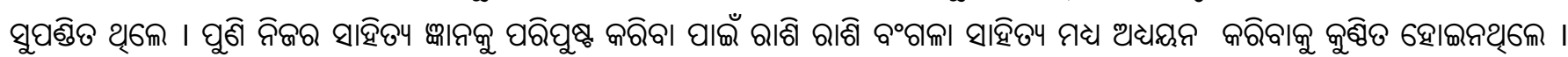

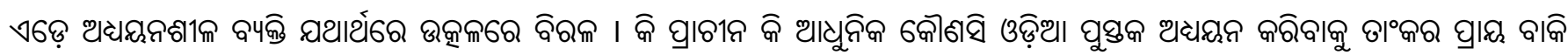
รขุญ! I" (9)

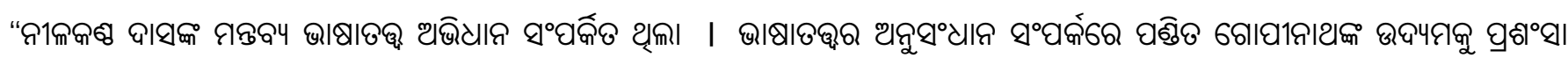

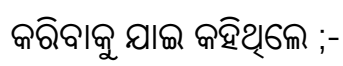

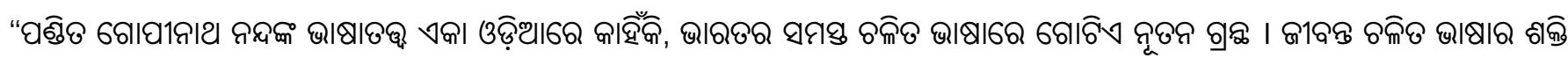

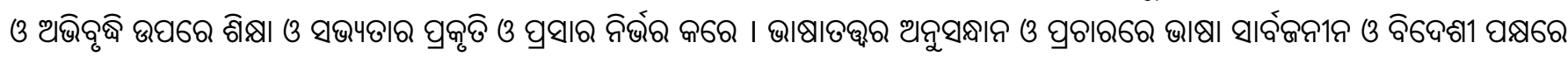
ઘু

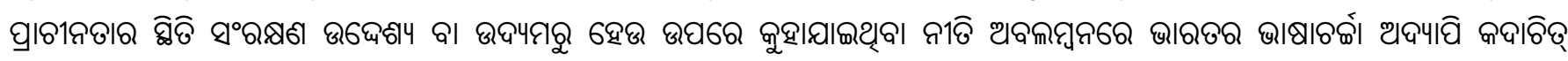

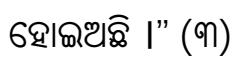

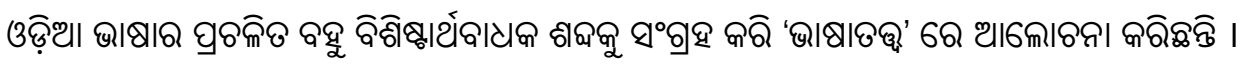

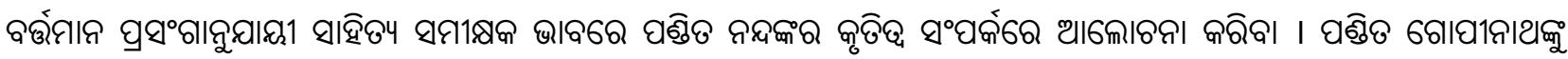

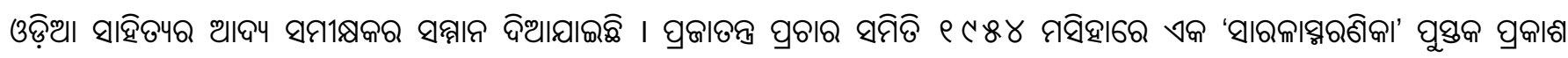

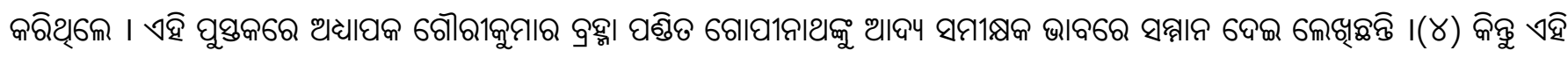

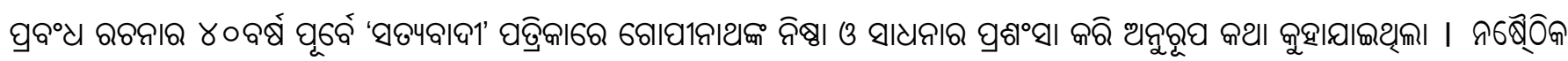

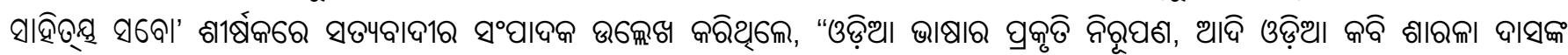

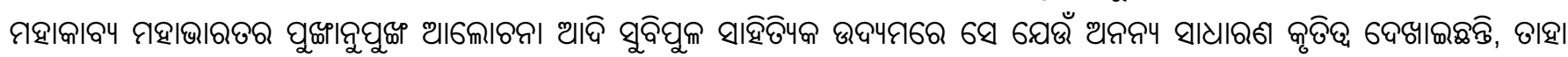

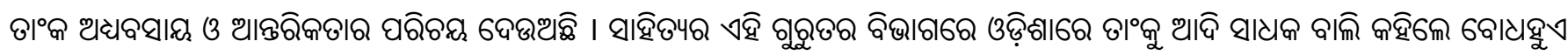

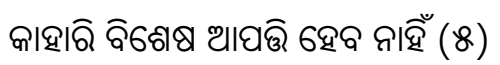

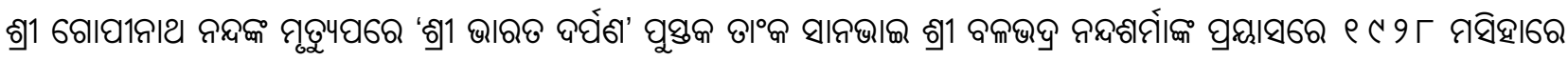

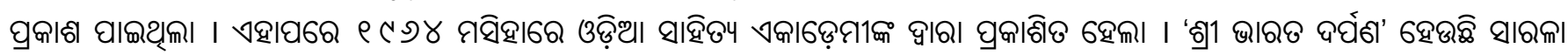

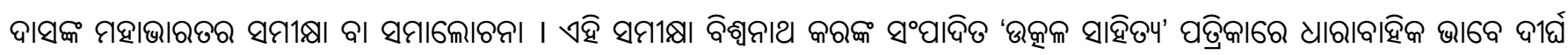

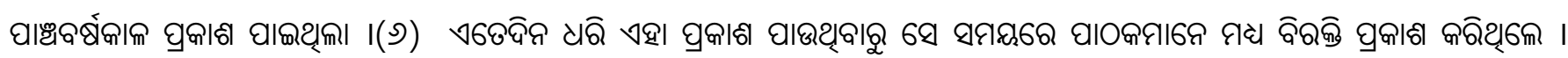

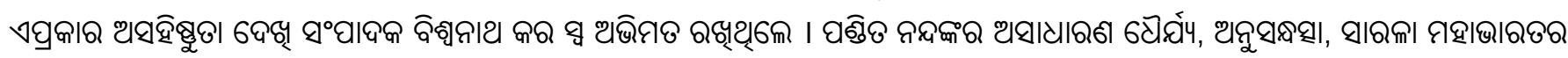




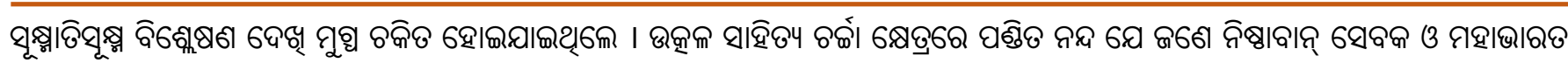

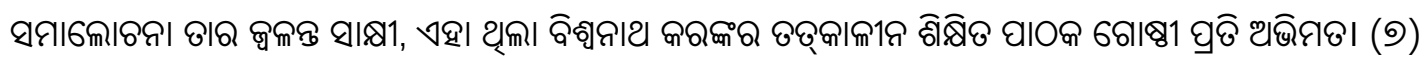

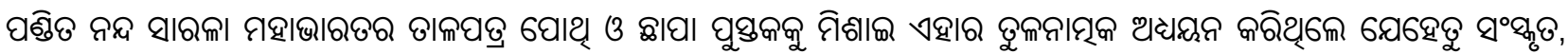

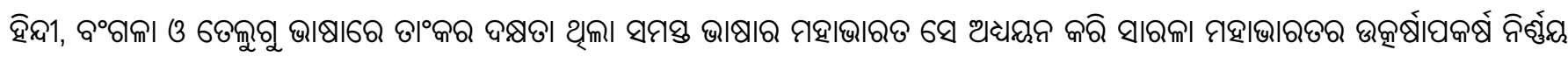

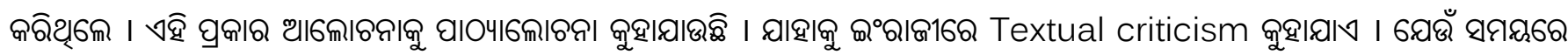

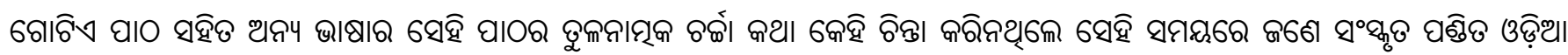

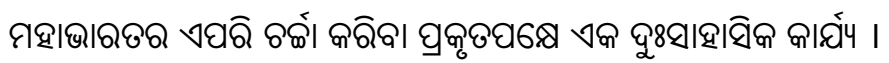

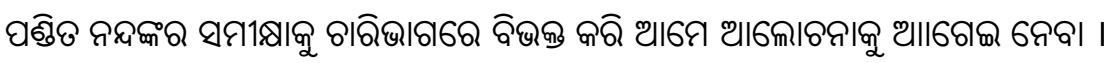

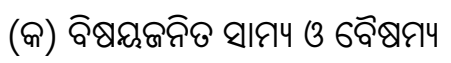

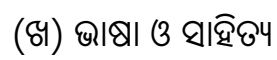

(ब) ติิ घลิธฯ

(๘) ๑घฮ॰๕। ।

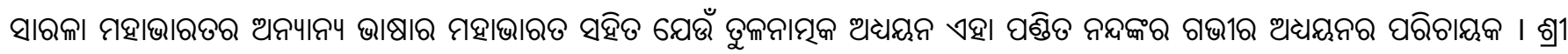

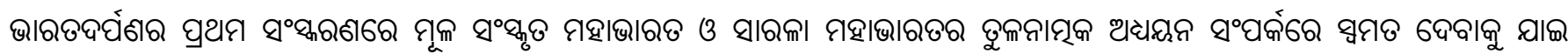

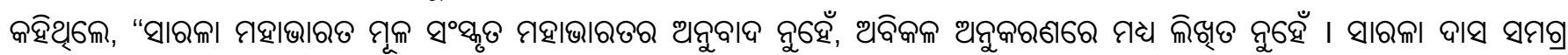

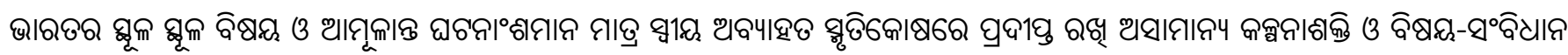

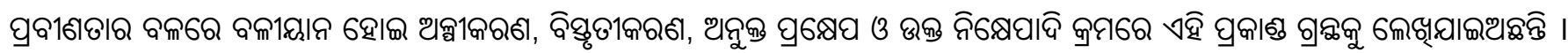

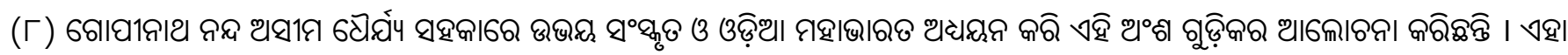

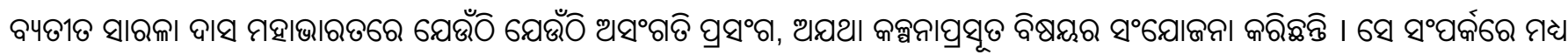

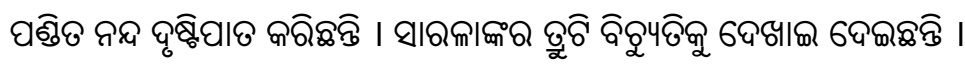

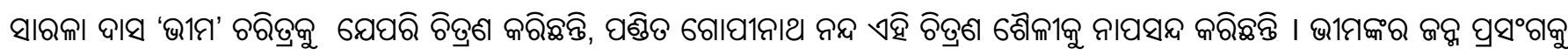

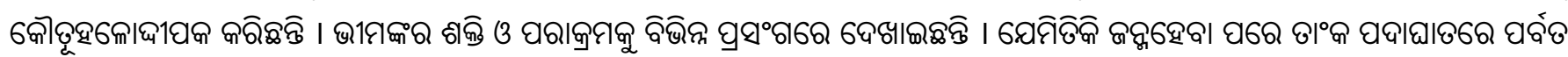

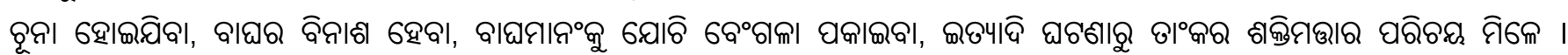

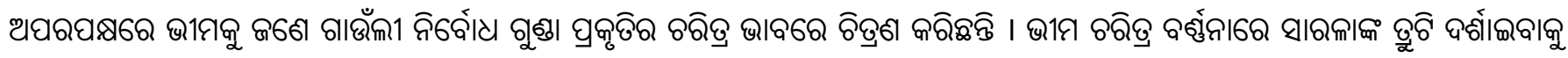

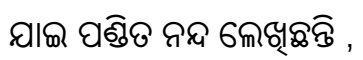

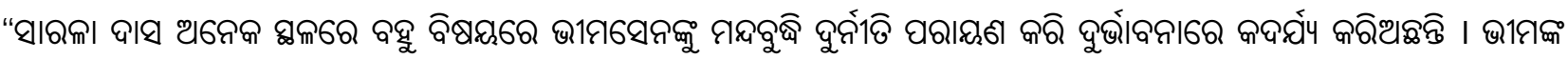

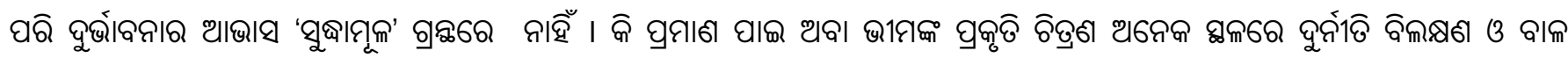

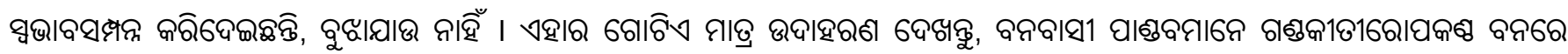

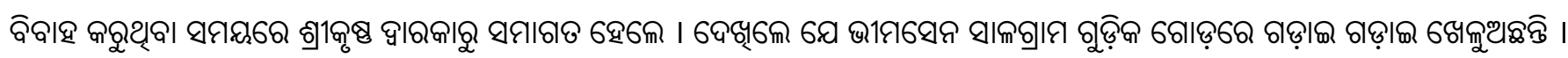

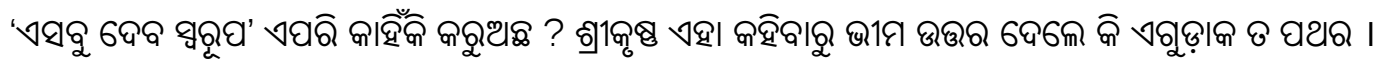

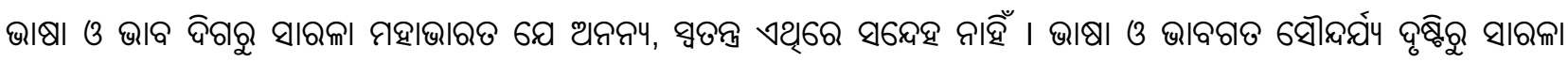

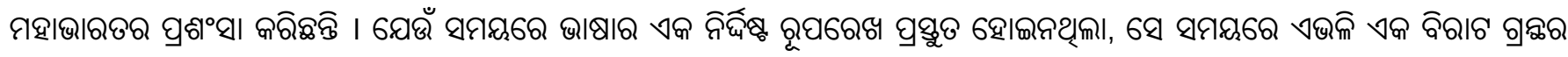

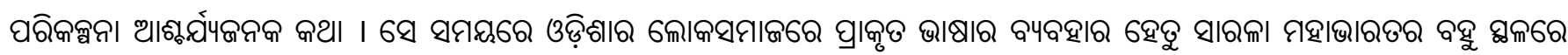

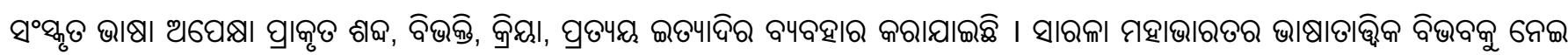

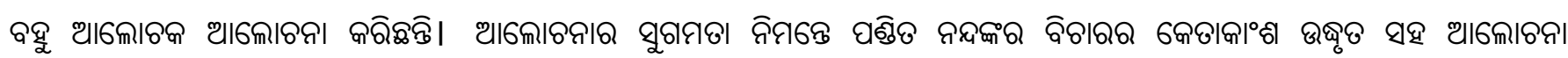

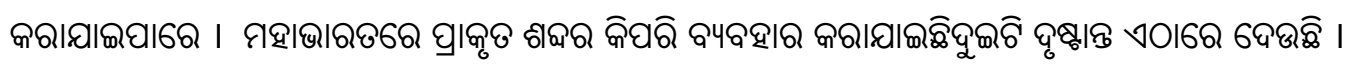

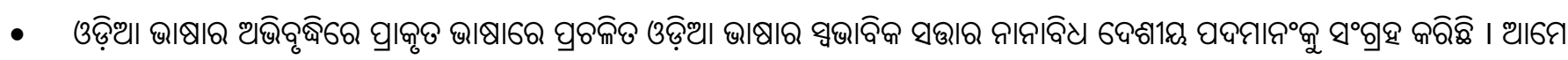

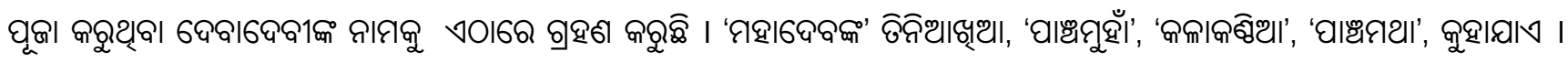

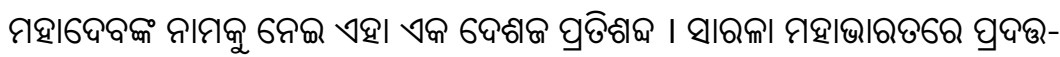




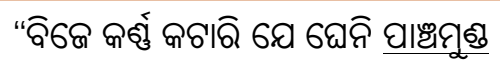

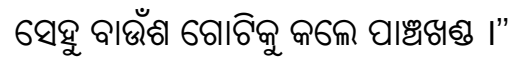

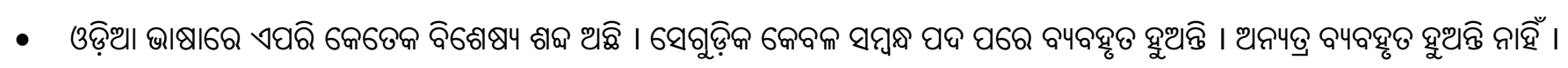

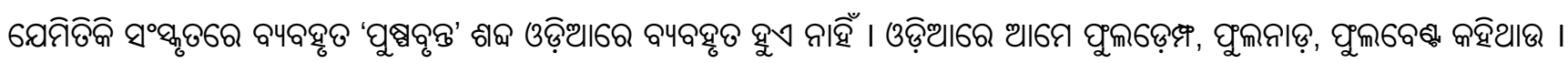

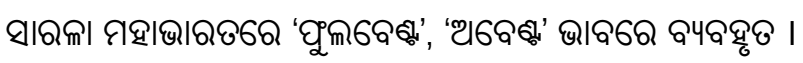

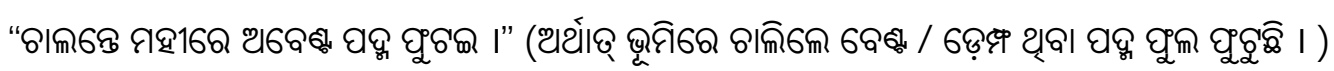

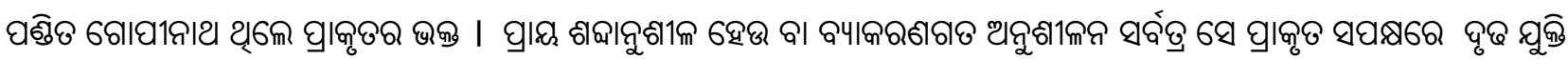

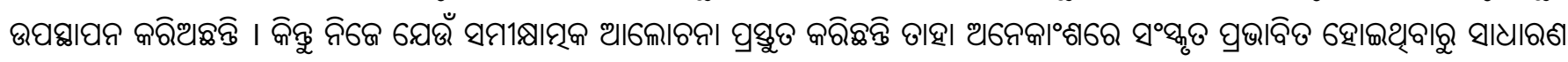

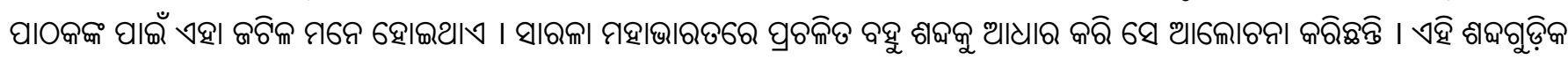

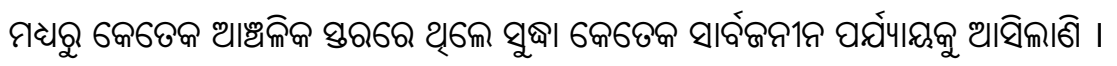

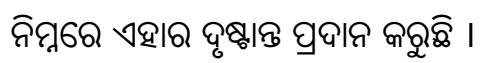

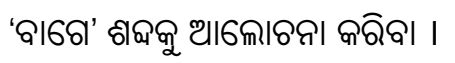

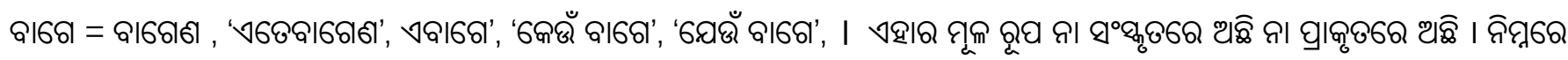

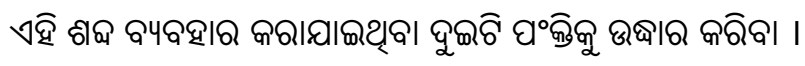

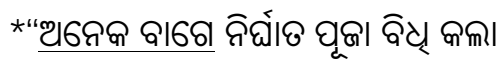

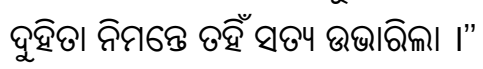

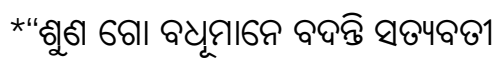

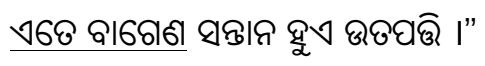

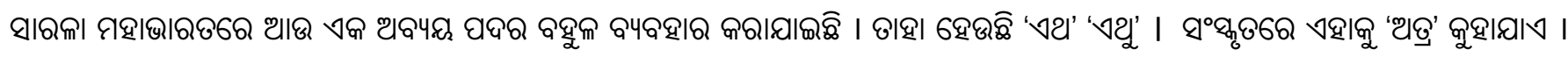

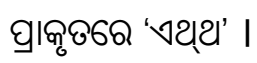

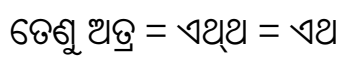

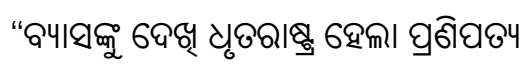

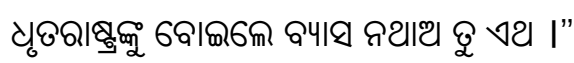

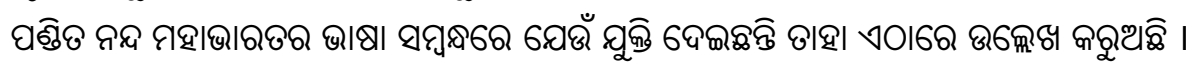

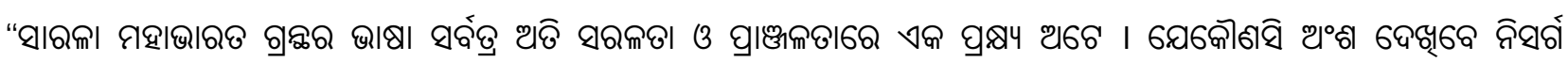

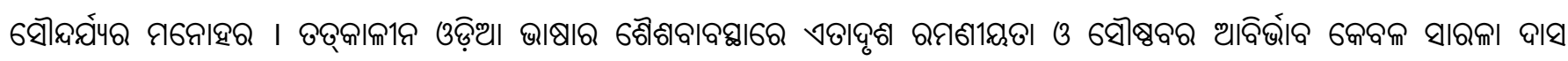

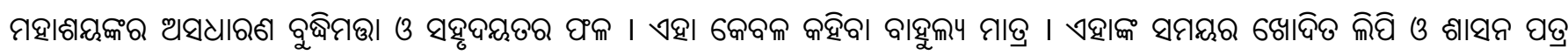

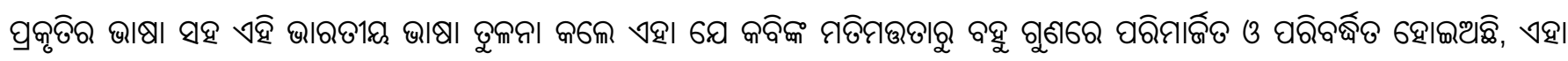

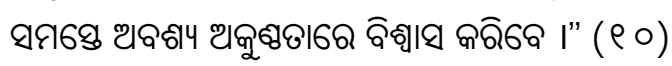

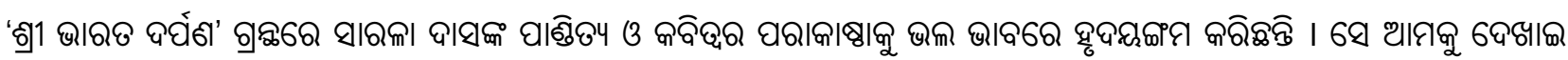

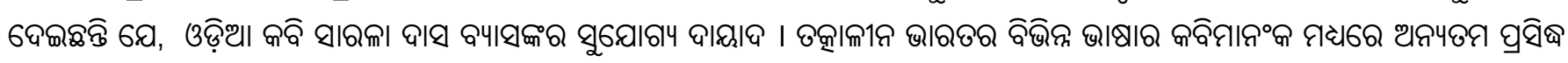

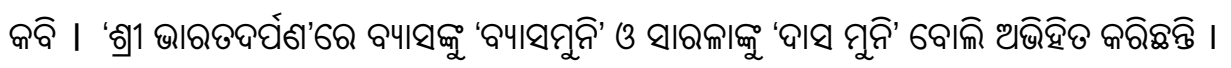

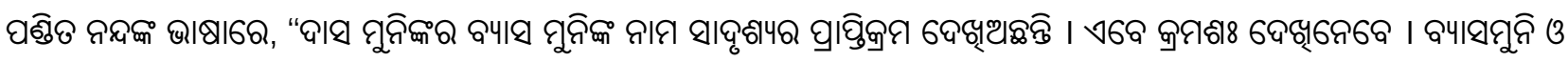

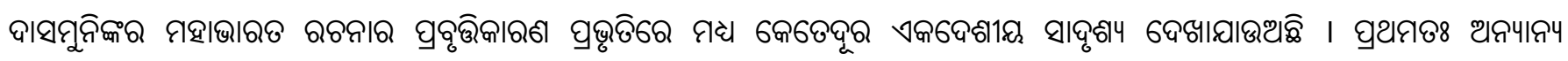

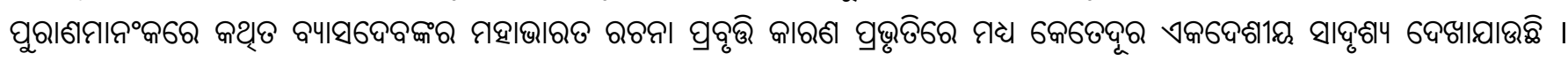

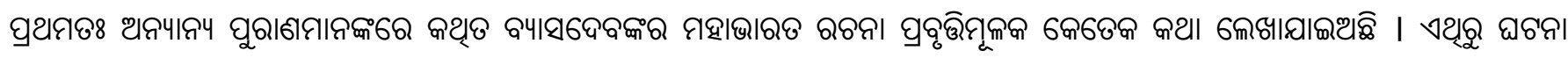

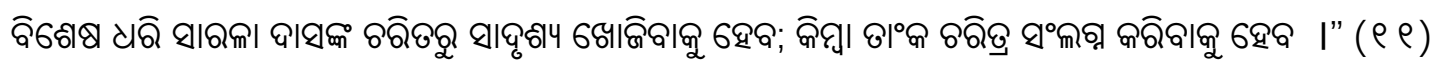




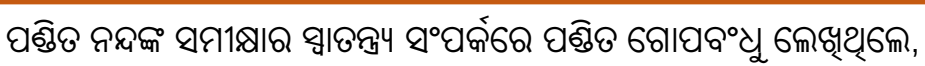

"The Pandit's labour and research in the domain of Oriya Literature are well known and his criticism of the Sarala Mahabharata fully justifies his reputation and would do credit to any eminent scholar of any language. He has noted the variations in the readings between the old palm leaf manuscripts and the printed works. A critical study of a gigantic work like the Mahabharata can be undertaken only by very few scholars of uncommon zeal and patience. There can be no doubt that Pandit Nanda's Samalochana (Criticism) is an invaluable contribution to Oriya literature." (12)

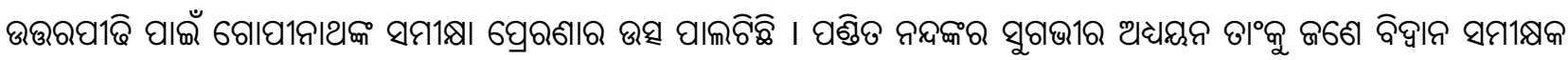

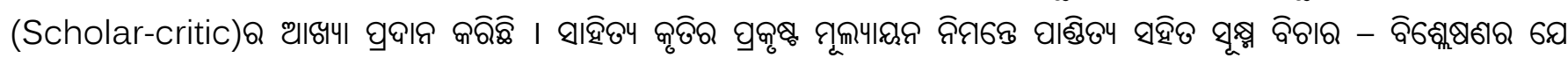

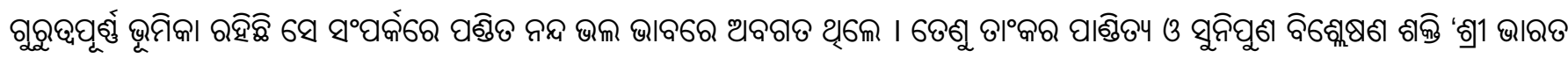

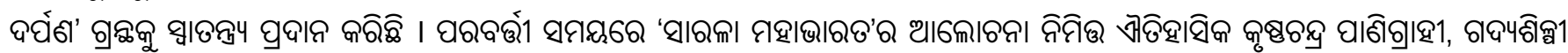

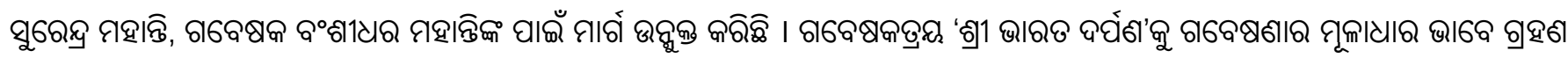

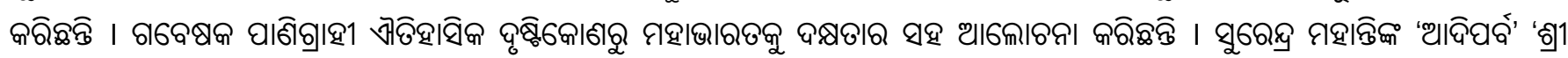

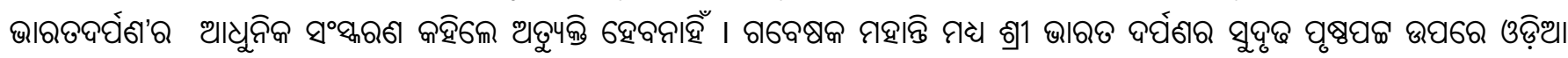

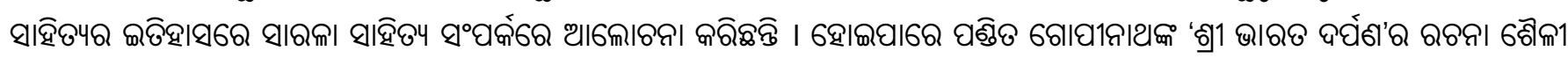

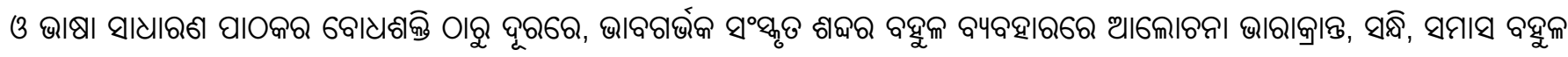

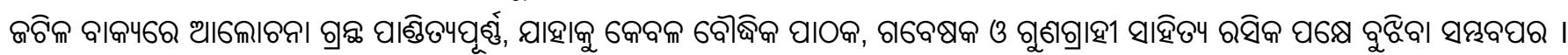

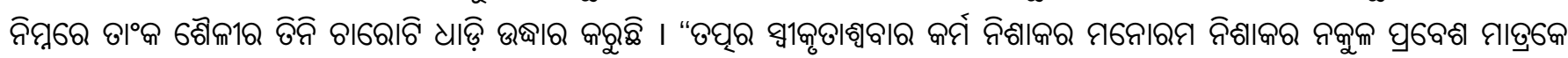

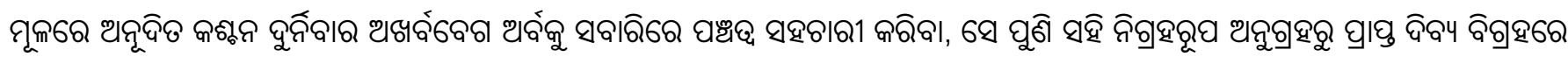

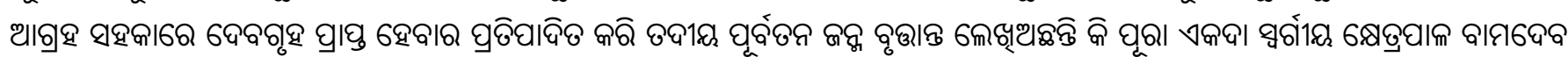

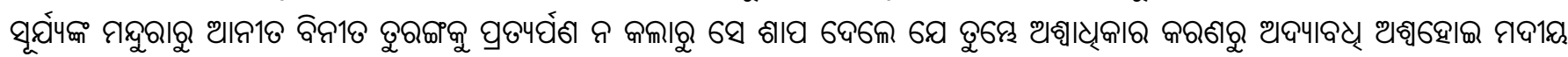

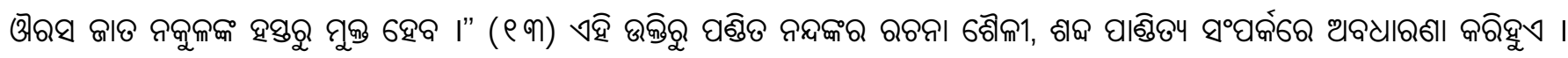

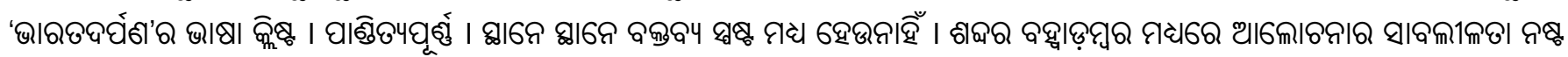

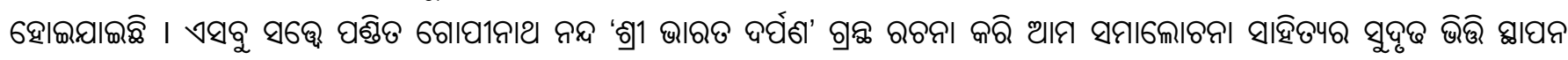
ติิฉุุ ।

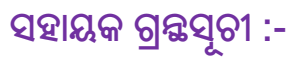

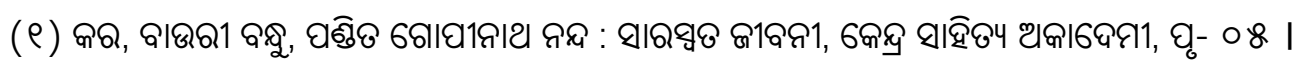

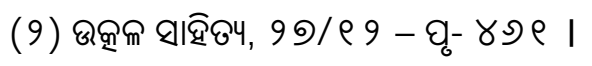

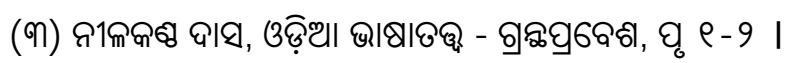

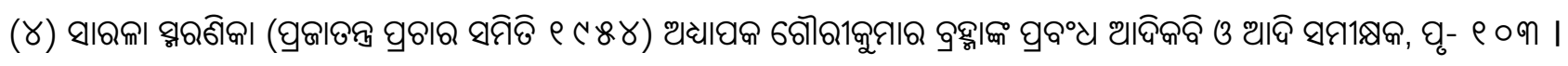

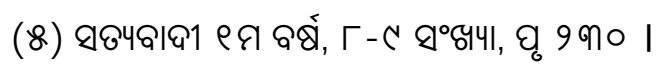

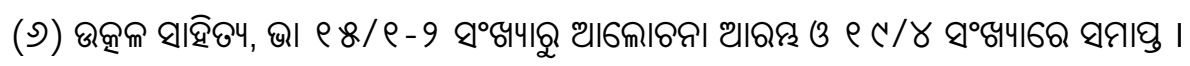

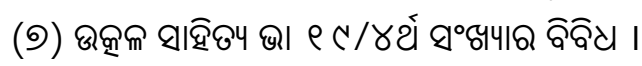

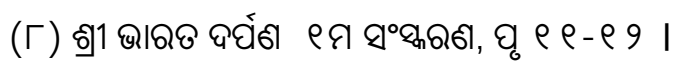

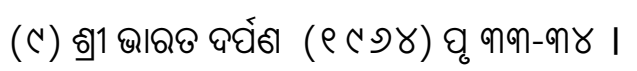

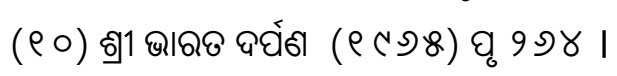




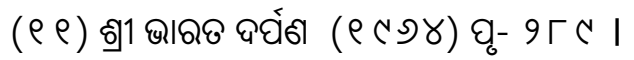

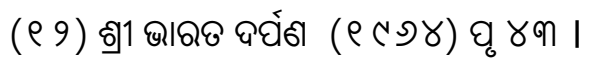

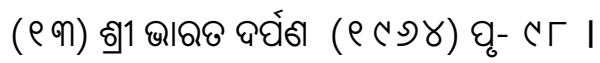

\section{Funding}

No funding was received for conducting this study.

\section{Conflict of interest}

The Author has no conflicts of interest to declare that they are relevant to the content of this article.

\section{About The License}

(C) The author 2020. The text of this article is open access and licensed under a Creative Commons Attribution 4.0 International License

\section{Cite this Article}

Bijayalaxmi Dash, Literary critic: pandit Gopinatha Nandasharma, Indian Journal of Multilingual Research and Development, Vol 1, Iss 1 (2020) 1-6. DOI: https://doi.org/10.34256/ijmrd2011 